\title{
Computer Vision Syndrome among Computer Operators Working at a Tertiary Care Hospital - A Study of Prevalence, Knowledge, Ergonomics and Other Associated Factors
}

\author{
Samreen Arif ${ }^{1}$, Jyoti Tulsani², Sajid Naqvi' ${ }^{3}$, Kavita Sharma ${ }^{4}$ \\ 1, 2, 3, 4 Health Center, Bhopal Memorial Hospital and Research Center Bhopal, Madhya Pradesh, India
}

\section{ABSTRACT}

\section{BACKGROUND}

Computer is an integral part of modern life. Millions of persons directly use computer by looking into VDTs (Video Display Terminals) for long time continuously which has been the cause of complex eye and vision problems which are experienced during or related to computer use called "Computer Vision Syndrome" (CVS). ${ }^{1}$ Prolonged computer use causes extreme discomfort while using of VDTs which in turn leads to low work productivity. Hence, it is very necessary to reduce computer use and find preventive measures for this emerging problem. The present study was designed to determine the prevalence and knowledge about CVS among computer operators of a tertiary care center and educate them about preventive measures and workplace ergonomics.

\section{METHODS}

The study was performed among 50 computer operators working at a tertiary care hospital. Detailed information about demographic profile, computer use, and questionnaire-based assessment of knowledge about CVS, workstation ergonomics and reassessing of knowledge after educating each study subject about CVS was done followed by comprehensive ocular examination of each study subject.

\section{RESULTS}

CVS was found to be present among $78 \%$ of computer operators. Most disturbing symptom in both male and female was sore/tired eyes (70\%) followed by neck and shoulder pain (64\%). CVS had resulted in eye problems in adverse environmental condition \& limitation of activity involving visual task in computer operators. There is high prevalence of CVS, in computer operators of BMHRC which might be due to poor knowledge of ergonomics, $>10$ years of computer use for 7 to 8 hours per day, and improper/not using of spectacles in workplace. There might be slight exaggeration of self-reported symptoms due to computer use by computer operators as it was questionnaire-based study.

\section{CONCLUSIONS}

The high prevalence of CVS and poor knowledge about workstation ergonomics in computer operators indicates the need for creating awareness about CVS, providing ocular health education, regular scheduled screening, and proper ergonomically designed workstation for computer operators and their regular comprehensive eye examination.

\section{KEY WORDS}

Computer Vision Syndrome, Ergonomics, Computer Professionals
Corresponding Author:

Dr. Samreen Arif,

H.No. 13, Sindhi Market Bhopal,

Madhya Pradesh - 462001, India.

E-mail: drsamreenarif@gmail.com

DOI: $10.14260 / \mathrm{jemds} / 2020 / 846$

How to Cite This Article:

Arif S, Tulsani J, Naqvi S, et al. Computer vision syndrome among computer operators working at a tertiary care hospital - a study of prevalence, knowledge, ergonomics and other associated factors. J Evolution Med Dent Sci 2020;9(51):38563861, DOI: 10.14260/jemds/2020/846

Submission 08-07-2020,

Peer Review 15-10-2020,

Acceptance 21-10-2020,

Published 21-12-2020.

Copyright $(2020$ Samreen Arifet al. This is an open access article distributed under Creative Commons Attribution License [Attribution 4.0 International (CC BY 4.0)] 


\section{BACKGROUND}

Computers have brought the biggest technological revolution in $21^{\text {st }}$ century because of their high efficiency and varied applications and contributions in different fields like online classes, recreation facilities etc at homes and workplaces.1,2 Despite these contributions excessive use of computers resulted in prolonged and continuous staring at Video Display Terminal (VDT) commonly known as computer screen which has resulted in complex disorder called "Computer Vision Syndrome" (CVS). ${ }^{3}$ Computer vision syndrome (CVS) is defined as a complex of eye and vision problems related to near vision tasks which occurs during and/or after the use of computers and prolonged viewing of the video display terminals (VDT) by American Optometric Association. ${ }^{4}$

CVS symptoms can be classified as ocular and non-ocular respectively. Ocular symptoms can further be classified as ocular surface abnormalities \& accommodative spasm. Ocular surface abnormalities resulted in symptoms of redness, dryness and irritation in eyes, burning sensation in eyes, watering, ocular strain/fatigue, blurring of vision, glare, extreme sensitivity to light and contact lens intolerance. Accommodative spasm related to computer use is the cause of ocular strain/fatigue, blurring of vision, transient diplopia, headache \& slowness in changing focus. Neck \& shoulder pain and backache is because of extra ocular aetiology. It has been evident from different studies that in the same environment persons who use VDT have more problems and ocular complaints as compared to non-users. ${ }^{5}$ The most commonly reported health problem because of VDT use is vision-related problems which are multifactorial and occurs in over $70 \%$ of computer workers. ${ }^{6}$ Many researchers have found that visual symptoms related to computer use increases with continuous extended exposure to computer screens although there is no strong evidence about its causation.7,8,9,10

Talwar et al \&Parihar et al in their studies found that refractive error \& presbyopia which are uncorrected, and binocular vision abnormalities are additional factors causing visual symptoms related to computer use.4,6 Other factors that contributed to the development of complaints and symptoms related to computer use are environmental factors, poor computer workstation design, and workplace ergonomics. Rosenfield in his study enumerated improper lighting, imbalance between computer screen and surrounding illumination, age and sex of computer user, and some systemic diseases as additional environmental or external risk factors for CVS. ${ }^{11}$

The arrangement of equipment and furniture in work place for users to work more efficiently and comfortably is referred to as workplace ergonomics. ${ }^{12}$ Proper positioning of keyboard, monitor, mouse, chairs, desks, document folders, seat height, width, depth, material, backrest, armrest, thickness of work surface, document holder and so on which facilitate comfortable and efficient working on computer in work place is referred to as visual or computer ergonomics.7,13,14 S. C. Reddy et al in their study reported that users with their computer screens set below the eye level had significantly lower CVS case than those who viewed the screen at or above the eye level. ${ }^{15}$ Study done by Mashige et al on Nonpresbyopic University staff in South Africa found that they had poor ergonomic set up at workstations and were ignorant of ergonomic standards for computer use. ${ }^{16}$
Various previous studies have reported measures to alleviate the symptoms of CVS which include frequent blinking (12-18/minute), short-time breaks after every 20 minutes to look at distant object at least 20 feet away for 20 seconds (2020-20 rule), adjustment of workstation, good sitting posture, appropriate lighting and screen brightness, and regular stretching of arms, leg, back, neck, and shoulders. ${ }^{4,13,17}$

The present study was designed to determine the prevalence of CVS, pre- and post-education assessment of knowledge of CVS, identification of associated risk factors for CVS among computer operators working in Tertiary care hospital in Central India.

\section{METHODS}

The study was done on 50 computer operators working in a Tertiary Care Hospital who consent to participate in study after prior permission from Institutional Ethical Committee. The study was a descriptive cross-sectional study in which computer operators had to undergo three phases under supervision of trained personnel. In first phase, each computer operator had answered a validated computer vision syndrome questionnaire (CVS-Q).

The questionnaire required computer operator to fill details about demographics that include age, gender, the educational qualification, the electronic device used, assessment of knowledge of CVS, symptoms pertaining to CVS, computer working hours, breaks taken while computer use, computer screen position, use of antiglare filter over computer screen, eye glass / contact lens use and work place ergonomics. The computer operators were asked regarding the frequency of symptoms as; never, rarely, often, or most of the time. They were also asked regarding appearance of symptoms along with frequency while doing specific visual task and in specific environmental conditions as sometime, half of the time, most of the time. On the basis of CVS symptoms in CVS-Q ${ }^{18}$ questionnaire the participants were divided into CVS ( $\geq 6$ SCORE) and Non-CVS ( $<6$ SCORE).

Second phase, each study participants underwent comprehensive ophthalmic evaluation by Ophthalmologist that includes refraction, slit lamp examination and fundus examination (if required).

Third phase the participants were educated about CVS and their preventive measures through a power point presentation followed by reassessing their knowledge by asking them predesigned questions.

\section{Statistical Analysis}

SPSS version 22 programme was used for statistical analysis. $P$ value was calculated by Chi square test.

\section{RESULTS}

The study was done on 50 computer operators (64\% were male and $36 \%$ were females) working at Tertiary Care Hospital. Male to female ratio was 16:9. The mean age of study participants were $37.2 \pm 7.39$ years with majority of participants (24\%) were 31 -35 yrs. age group. Among all 
participants youngest was 24 years and eldest was 59 years old. Maximum number of participants was postgraduates (54 $\%$ ) and rest of them was undergraduates (46\%). [Table I]

\begin{tabular}{|c|c|c|c|}
\hline $\begin{array}{c}\text { Sl. } \\
\text { No. }\end{array}$ & Parameters & & Details \\
\hline 1 & Average age & Mean \pm SD & $37.32 \pm 7.39$ \\
\hline \multirow[t]{5}{*}{2} & Sex & & \\
\hline & Male & Number & 32 \\
\hline & & Percentage & $64 \%$ \\
\hline & Female & Number & 18 \\
\hline & & Percentage & $36 \%$ \\
\hline \multirow[t]{5}{*}{3} & Education & & \\
\hline & Graduation & Number & 23 \\
\hline & & Percentage & $46 \%$ \\
\hline & Masters & Number & 27 \\
\hline & & Percentage & $54 \%$ \\
\hline \multirow[t]{3}{*}{4} & Computer use & & \\
\hline & Average number of hours & Mean \pm SD & 7.56 hours \pm 1.23 \\
\hline & Average number of years & Mean \pm SD & 13.38 years \pm 5.72 \\
\hline \multirow[t]{3}{*}{5} & $\begin{array}{l}\text { Assessment of knowledge } \\
\text { (\% of correct answers) }\end{array}$ & & \\
\hline & Pre education score & & $34.4 \%$ \\
\hline & Post education score & & $64.66 \%$ \\
\hline & Table I. General Det & of Participc & \\
\hline
\end{tabular}

Average number of years of computer use by participants is $13.38 \pm 5.72$ years. Majority of participants (34\%) were using computer since 11-15 years. Average number of hours of computer use by participants is $7.56 \pm 1.23$ hours. $100 \%$ of participants were using desktop with overhead fluorescent lightening in work area. $50 \%$ (26\% laptop \& $24 \%$ desktop) participants use computer at home. Average time spent on computer by participants at work is 7.36 hours, at home is 0.83 hours and on smart phone is 1.58 hours.

The average viewing distance (in inches) of eye to computer screen is 28.62 (29.87 inches in males \& 26.38 inches in females), to keyboard is 20.9 and to reference material is 20.84 inches. Level of computer screen was above eye level in $12 \%$ of participants ( $8 \%$ males \& $4 \%$ females), at eye level in $68 \%$ (38\% males \& $30 \%$ females) and below eye level in $20 \%$ participants (18\% males and $2 \%$ females). $18 \%$ of participants use printed reference material at eye level and $82 \%$ below eye level.

Poor knowledge and awareness about workstation ergonomics and computer vision syndrome were found in computer operators as evident by percentage of correct answers assessed by questionnaire which was $34.4 \%$ and improved to $64.66 \%$ after educating computer operators regarding computer vision syndrome and ergonomics. [Table II].

$94 \%$ of participants had symptoms/complaints suggestive of CVS. $100 \%$ of female and $90.62 \%$ of male participants suffer from one or more symptoms of CVS. $76 \%$ participants believe that these symptoms are related to computer use, 16 $\%$ think there might be some other reason for them and $2 \%$ did not have any idea about the cause of their symptoms. The prevalence of CVS on the basis of CVS Q questionnaire score $\geq$ 6 was found to be $76 \%$. Most disturbing symptom in both male and female was sore/tired eyes (70\%) followed by neck \& shoulder pain (64\%). $12 \%$ of participants do not take any measure to get relief from symptoms. $88 \%$ take measures which includes take break and move around (42\%), take break and remain seated (36\%), close eyes ( $40 \%$ ), blink more frequently (6\%). $26 \%$ take more than one measure to get relief from their symptoms. [Table III] [Table IV].

$38 \%$ participants were using glasses $(16 \%$ for distance, $16 \%$ both for distance and near, $6 \%$ for near), out of which 14 $\%$ were given new spectacle correction as they were using wrong correction.

\begin{tabular}{|c|c|c|}
\hline $\mathbf{A}$ & $\begin{array}{l}\text { Average Time Spent on Computer } \\
\text { (in Hours) }\end{array}$ & \\
\hline & At work & 7.36 hours \pm 1.04 \\
\hline & At home & 0.83 hours \pm 1.36 \\
\hline & On smart phone & 1.58 hours \pm 1.89 \\
\hline \multirow[t]{6}{*}{ B } & Computer use at work & \\
\hline & Desktop & $100 \%$ \\
\hline & Laptop & 0 \\
\hline & Computer use at home & \\
\hline & Desktop & $24 \%$ \\
\hline & Laptop & $26 \%$ \\
\hline \multirow[t]{3}{*}{$\mathbf{C}$} & Use of glasses while computer use & \\
\hline & Yes & $38 \%$ \\
\hline & No & $62 \%$ \\
\hline \multirow[t]{3}{*}{ D } & Use of contact lenses while computer use & \\
\hline & Yes & 0 \\
\hline & No & 100 \\
\hline \multirow[t]{3}{*}{$\mathbf{E}$} & Use of reference matter while computer use & \\
\hline & Yes & $86 \%$ \\
\hline & No & $14 \%$ \\
\hline \multirow[t]{4}{*}{$\mathbf{F}$} & Average viewing distance(in inches) from eye to & \\
\hline & Computer screen & $28.62 \pm 8.64$ inches \\
\hline & Keyboard & $20.9 \pm 9.64$ inches \\
\hline & Reference material & $20.84 \pm 9.48$ inches \\
\hline \multirow[t]{4}{*}{ G } & Level of computer screen as compare to eye & \\
\hline & Above & $12 \%$ \\
\hline & Equal & $68 \%$ \\
\hline & Below & $20 \%$ \\
\hline \multirow[t]{4}{*}{$\mathbf{H}$} & Level of Reference material as compare to eye & \\
\hline & Above & 0 \\
\hline & Equal & $18 \%$ \\
\hline & Below & $82 \%$ \\
\hline \multirow[t]{6}{*}{ I } & $\begin{array}{l}\text { Limitation of activity involving visual task because } \\
\text { of computer use }\end{array}$ & \\
\hline & Reading & $30 \%$ \\
\hline & Driving at night & $32 \%$ \\
\hline & Working with computer & $44 \%$ \\
\hline & Watching television & $42 \%$ \\
\hline & None & $36 \%$ \\
\hline \multirow[t]{5}{*}{$\mathbf{J}$} & $\begin{array}{c}\text { Eye problems in adverse environmental } \\
\text { conditions }\end{array}$ & \\
\hline & Windy areas & $40 \%$ \\
\hline & Dry areas & $28 \%$ \\
\hline & Air conditioned areas & $22 \%$ \\
\hline & None & $42 \%$ \\
\hline & Table II. Details Related to Computer & Use \\
\hline
\end{tabular}

\begin{tabular}{|c|c|c|c|c|c|c|c|}
\hline \multirow{3}{*}{$\begin{array}{l}\text { S. } \\
\text { No. }\end{array}$} & \multirow{3}{*}{ Symptoms } & \multirow{2}{*}{\multicolumn{2}{|c|}{$\begin{array}{c}\text { Male } \\
\text { Participants }\end{array}$}} & \multirow{2}{*}{\multicolumn{2}{|c|}{$\begin{array}{c}\text { Female } \\
\text { Participants }\end{array}$}} & \multicolumn{2}{|c|}{$\begin{array}{c}\text { Total } \\
\text { Participants }\end{array}$} \\
\hline & & & & & & \multirow{2}{*}{ No } & \multirow{2}{*}{$\%$} \\
\hline & & No. & $\%$ & No & $\%$ & & \\
\hline A & Redness and itching & 11 & $22 \%$ & 11 & $22 \%$ & 22 & $44 \%$ \\
\hline B & Sandy or gritty sensation & 6 & $12 \%$ & 10 & $20 \%$ & 16 & $32 \%$ \\
\hline $\mathrm{C}$ & Glare (light) sensitivity & 11 & $22 \%$ & 6 & $12 \%$ & 17 & $34 \%$ \\
\hline D & Sore / tired eyes & 20 & $40 \%$ & 15 & $30 \%$ & 35 & $70 \%$ \\
\hline $\mathrm{E}$ & Dry / watery eyes & 16 & $32 \%$ & 10 & $20 \%$ & 26 & $52 \%$ \\
\hline $\mathrm{F}$ & Fluctuation / blurred vision & 16 & $32 \%$ & 4 & $8 \%$ & 20 & $40 \%$ \\
\hline G & Double vision & 9 & $18 \%$ & 3 & $6 \%$ & 12 & $24 \%$ \\
\hline $\mathrm{H}$ & Headache & 15 & $30 \%$ & 10 & $20 \%$ & 25 & $50 \%$ \\
\hline I & Back pain & 17 & $34 \%$ & 13 & $26 \%$ & 30 & $60 \%$ \\
\hline $\mathrm{J}$ & Neck \& shoulder pain & 18 & $36 \%$ & 14 & $28 \%$ & 32 & $64 \%$ \\
\hline \multicolumn{8}{|c|}{$\begin{array}{l}\text { Table III. Distribution According to Symptoms } \\
\text { Related to CVS with Average Severity Score }\end{array}$} \\
\hline
\end{tabular}




\begin{tabular}{|cccc|}
\hline Sl. & Measures Taken & \multicolumn{2}{c|}{ Participants } \\
No. & & Number & Percentage \\
& Blink more frequently & 6 & $12 \%$ \\
1 & Close eyes & 20 & $40 \%$ \\
2 & Take break and move around & 21 & $42 \%$ \\
3 & None & 6 & $36 \%$ \\
4 & Take break and remain seated & $18 \%$ \\
\hline 5 & Table IV. Measures Taken to Get Relieved \\
\hline \multicolumn{3}{|c}{ fromptoms Due to Computer Use } \\
\hline
\end{tabular}

Out of $62 \%$ participants who were not using glasses $24 \%$ need spectacle correction which was given to them and $38 \%$ did not require any spectacle correction. $100 \%$ participants do not use contact lenses while using computer.

$64 \%$ of participants (38\% males, $26 \%$ females) have limitation of activity (reading $30 \%$, VAD use $44 \%$, watching television $42 \%$, driving at night $32 \%$ ) because of their eye problems. More number of participants who had limitation of daily activity because of eye problems were in age group $36-$ 40 years (females $>$ males in this group). $48 \%$ of participants (24\% male, $24 \%$ female) have eye problems in adverse environmental conditions (19\% windy, $15 \%$ dry area, $11 \%$ air-conditioned areas). More number of participants and having eye problems in adverse environmental condition were in age group $26-30$ yrs. (males $>$ females in this age group). [Table V]. $48 \%$ of the participants were found to have either refractive error or ocular surface disorder for which appropriate treatment was given.

\begin{tabular}{|c|c|c|c|c|c|c|c|c|}
\hline \multirow{3}{*}{ Sex } & \multicolumn{4}{|c|}{$\begin{array}{l}\text { Activity Limitation because of } \\
\text { Eye Problems }\end{array}$} & \multicolumn{4}{|c|}{$\begin{array}{l}\text { Eye Problems in Adverse } \\
\text { Environmental Conditions }\end{array}$} \\
\hline & \multicolumn{2}{|c|}{ Yes } & \multicolumn{2}{|c|}{ No } & \multicolumn{2}{|r|}{ Yes } & \multicolumn{2}{|c|}{ No } \\
\hline & Number & $\%$ & Number & $\%$ & Number & Percentage & Numb & $\begin{array}{l}\text { Percent } \\
\text { age }\end{array}$ \\
\hline $1 \quad$ Male & 19 & $38 \%$ & 13 & $26 \%$ & 12 & $24 \%$ & 20 & $40 \%$ \\
\hline 2 Female & 13 & $26 \%$ & 5 & $10 \%$ & 12 & $24 \%$ & 6 & $12 \%$ \\
\hline Total & 32 & $64 \%$ & 18 & $36 \%$ & 24 & $48 \%$ & 26 & $52 \%$ \\
\hline
\end{tabular}

\section{DISCUSSION}

This study was done on computer operators of Tertiary Care Hospital to estimate the occurrence of Computer Vision Syndrome (CVS) and also to find possible association of CVS symptoms with various ergonomic factors. CVS symptoms were found in $78 \%$ of our study participants, the results were comparable to observations made by different investigators. ${ }^{19}$

The mean age of study participants were 37.2 with majority of participants (24\%) were 31 -35 yrs. age group.

The reason for increased prevalence of CVS in our study participants might be due to all the study participants were working on computer on an average of 7-8 hours per day for about $>10$ years. $100 \%$ of female and $90.62 \%$ of male participants suffer from one or more symptoms of CVS and hence it can be concluded that females as compared to males were more prone to develop CVS symptoms, similar observation was reported by Shantakumari et al who also found higher CVS symptoms in females. ${ }^{6}$

Most disturbing symptom in both male and female was sore/tired eyes (70 \%) followed by pain in neck \& shoulder (64\%), the findings are comparable to study done by Shantakumari et al \& Akinbinu and Mashalla who reported eye soreness as the commonest symptom and most disturbing symptom.6,20 The reason for sore / tired eyes resulting in headache might be as the eyes have to adjust constantly due to constant refocusing of eyes while viewing computer screen and reference material, condition become worse if eye glasses without correct prescription were used. There is difference in response of eyes and brain while reading character on computer screen and to printed character. Eyes are much comfortable in focusing printed material as compared to computer screen, as center character (pixels) on computer screen are brighter as compared to character at the edges of the screen as intensity diminishes from center towards their edges making it very difficult for eyes to remain fixed and maintain focus.

The most common non ocular symptoms were neck and shoulder pain followed by back pain, this might be due to awkward unnatural posture adopted by computer operators. Many reporters have reported positive significant association between eye strain \& neck shoulder symptoms. ${ }^{19,21}$ The study done by Sheedy et al. ${ }^{22}$ suggested that ocular CVS symptoms can change the posture while computer use resulting in increased time taken to complete a task and decreased work productivity as compared to someone without symptoms. The possible pathophysiology for this can be prolong viewing of computer screen results in lower blinking rate causing eye moisture to evaporate leading to dryness. In an attempt to relieve CVS symptoms many people can assume awkward, unnatural postures thus causing sore back, stiff neck and hurting shoulders. They may arch their foreheads in effort to see better, thus causing headaches.

$38 \%$ of participants were given proper spectacle correction (14\% using wrong correction \& $24 \%$ were not using any spectacles). Uncorrected refractive errors can lead to increase mental stress, reduced effective working hour, increase risk of errors and frequent absence from work leading to reduced productivity.

The average viewing distance from the display screen among study participants were 28.62 inches which is different from viewing distance less than 25 inches among $26.2 \%$ subject reported by Stella C et al. ${ }^{23}$ Increased viewing distance by study participants might be in an anticipation to decrease CVS symptoms and eye strain as increased viewing distance may allow the eyes to relax. ${ }^{24}$

The study participants were found to be having poor knowledge regarding workstation ergonomics and computer vision syndrome as evident by pre-education score $34.4 \%$ which improved to $64.66 \%$ after educating computer operators regarding computer vision syndrome and ergonomics. This might be the significant predictors of complaints related to computer use hence implementation of worksite ergonomics\& awareness programs may be cost effective preventive measure to reduce work related complaints, medical expenses and to improve work productivity. ${ }^{25,26}$

Majority of participants having limitation of activity involving visual task due to eye problems were in age group 36 - 40 yrs. (female > male) can be attributed to female gender and decreasing ciliary body muscle contractibility. Majority of participants having eye problems in adverse environmental condition (windy/dry/air-conditioned areas) were males in age group 26 - 30 years, this might be attributed to these persons more involved in outdoor activities. 


\section{CONCLUSIONS}

In our study, increased prevalence of CVS was found among computer operators working in a Tertiary Care Hospital. It might be due to their poor knowledge about workstation ergonomics, $>10$ years of computer use for 7 to 8 hours per day \& improper/not use of spectacles in workplace. Majority of them (64\%) have limitation of activity involving visual task due to eye problems, $48 \%$ have eye problems in adverse environmental conditions (windy / dry / air-conditioned areas).

The limitation of our study was small sample size, the participants may under or over report their CVS symptoms depending upon their mood and personality as it is a questionnaire-based study and involves subjective assessment of CVS symptoms and workstation ergonomics.

Computer use which is high visual demanding task has become an integral part of modern life that resulted in a new era of professional risk among computer users of computer vision syndrome (CVS). As most of the computer professionals are ignorant of this evolving occupational hazard called Computer Vision Syndrome, it remains an undiagnosed, illdefined and underrated problem at workplace despite its wide prevalence. Depending on severity and persistence of disorder, CVS can cause deterioration in performance, abstinence from work leading to decrease in work productivity and increased medical expenses.

Successful management of CVS requires a multidirectional approach. Abstinence from the cause must have been an ideal solution but in case of CVS it is not possible practically because of excessive use of computers in day-to-day life. Hence prevention is the key for managing CVS that can be done by creating awareness and providing health education to computer operators, modification of workstation ergonomics; regular screening programmes that can be questionnaire based for early identification of CVS symptoms. Modification of workstation ergonomics like level of computer screen below eye level, proper viewing distance from the screen and reference material, proper height of workstation chair, properly lilted copy stands for reference material, position of AC, appropriate brightness of the screen \& surrounding, use of anti-glare filters on screen, correct prescription eyeglasses with anti-glare coating, regular breaks, etc can be done to prevent CVS. Computer operators should undergo scheduled regular comprehensive eye examination along with appropriate ocular therapy.

Data sharing statement provided by the authors is available with the full text of this article at jemds.com.

Financial or other competing interests: None.

Disclosure forms provided by the authors are available with the full text of this article at jemds.com.

\section{REFERENCES}

[1] BlehmC, VishnuS, KhattakA, et al. Computer vision syndrome: a review. Surv0phthalmol2005;50(3)253-62.

[2] SinghJD, Davidson J, Cottage M. Computers and your health-protecting yourself from computer related health issues. Mendon, UT, USA: JD-Biz Publishing 2015.
[3] Logaraj M, Madhupriya V, Hegde SK. Computer vision syndrome and associated factors among medical and engineering students in Chennai. Ann Med Health Sci Res 2014;4(2):179-85.

[4] American Optometric Association. Guide to the clinical aspects of computer vision syndrome.St. Louis, MO, USA: American Optometric Association 1995.

[5] Talwar R, Kapoor R, Puri K, et al. A study of visual and musculoskeletal health disorders among computer professionals in NCR Delhi. Indian JCommunity Med 2009;34(4):326-8.

[6] PariharJKS, JainVK, ChaturvediP, et al. Computer and visual display terminals(VDT) vision syndrome (CVDTS). Medical J Armed Forces India2016;72(3):270-6.

[7] LecceseF, SalvadoriG, OnerM, et al. Exploring the impact of external shading system on cognitive task performance, alertness and visual comfort in a daylit workplace environment. Indoor and Built Environment 2019;29(7):1-14.

[8] BlaisBR. Visual ergonomics of the office workplace. Chemical Health and Safety1999;6(4):31-8.

[9] KanitkarK, CarlsonAN, RichardY. Ocular problems associated with computer use: the ever-increasing hours spent in front of video display terminals have led to a corresponding increase in visuals and physical ills. Review of Ophthalmology 2005;22(12):3-4.

[10] YanZ, HuL, ChenH, et al. Computer vision syndrome: a widely spreading but largely unknown epidemic among computer users. Computers in Human Behavior2008;24(5):2026-42.

[11] RosenfieldM. Computer vision syndrome: a review of ocular causes and potential treatments. OphthalmicPhysiol Opt 2011;31(5):502-15.

[12] AnshelJ.Visual ergonomics handbook. Abingdon, UK: Taylor \& Francis Group 2005:45-50.

[13] AnkrumDR. Visual ergonomics in the office-guidelines. Occupational Health \& Safety1999;68(7):64-74.

[14] LecceseF, SalvadoriG,RoccaM. Visual ergonomics of video-display-terminal workstations: field measurements of luminance for various display settings. Displays 2016;42:9-18.

[15] Reddy SC, Low CK, Lim YP, et al. Computer vision syndrome: a study of knowledge and practices in university students. Nepal J Ophthalmol2013;5(2):161-8.

[16] MashigeKP, Rampersad N,Oduntan OA. A study of ergonomic factors leading to computer vision syndrome among computer users. Ergonomics SA2013;25(1):3-12.

[17] MashigeKP. Occupational health southern Africacomputer-related symptoms in the workplace: causes and preventive strategies: back to basics. Occupational Health Southern Africa2014;20(3):13-7.

[18] SeguıMDM, Cabrero-GarciaJ, CrespoA, et al. A reliable and valid questionnaire was developedto measure computer vision syndrome at the workplace. JClinEpidemiol2015;68(6):662-73.

[19] http://www.copperwiki.org/index.php/Computer_Relat ed_Ailments

[20] AkinbinuTR, MashallaYJ. Knowledge of computer vision syndrome among computer users in the workplace in Abuja, Nigeria. JPhysiolPathophysiol2013;4(4):58-63.

[21] Hayes JR, Sheedy JE, StelmackJA, et al.Computer use, symptoms and quality of life. Optom Vis Sci 2007;84(8):738-44. 
[22] Sheedy J, Shaw-McMinn P. Diagnosing and treating computer related vision problems. $1^{\text {st }}$ edn. Butterworth Heinemann 2003:1-200.

[23] Chiemeke SC, Akhahowa AE, Ajayi OB. Evaluation of vision-related problems amongst computer users: a case study of University of Benin, Nigeria. Proceedings of the World Congress on Engineering 2007;1:2-6.

[24] Jaschinski W, Heuer H, Kylian H. Preferred position of visual displays relative to the eyes: a field study of visual strain and individual differences. Ergonomics 1998;41(7):1034-49.

[25] Cole DC, Hagg-Johnson S, Manno M, et al. Reducing musculoskeletal burden through ergonomic program implementation in large newspaper. Int Arch OccupEnviorn Health 2066;80(2):98-108.

[26] Hendrik HW. Proceedings of the $40^{\text {th }}$ Annual Meeting of the Human. Factors and ergonomics Society: 2-6 Sept 1996: Santa Monica. Human Factors and Ergonomics Society 1996:1-10. 